\section{Non-ataxia signs in Brazilian individuals with spinocerebellar ataxia type 3}

\author{
Sinais não-atáxicos em \\ indivíduos brasileiros com \\ ataxia espinocerebelar tipo 3
}

\begin{abstract}
Camilla Polonini Martins (D) ${ }^{1}$
Mariana da Silva Salvino Klem Galvez (D) ${ }^{2}$

Yuri Rodrigues Luz de Araujo (i) ${ }^{1}$

Leda Maria Neumann Keim (iD ${ }^{3}$

Fernanda Baseggio Lopes Figueiredo (1) ${ }^{1}$

Laura Alice Santos de Oliveira (10 ${ }^{1,3^{*}}$
\end{abstract}

\footnotetext{
${ }^{1}$ Centro Universitário Augusto Motta (UNISUAM), Graduate Program in Rehabilitation Sciences, Rio de Janeiro, RJ, Brazil

${ }^{2}$ Instituto Federal de Educação Ciência e Tecnologia do Rio de Janeiro (IFRJ), Rio de Janeiro, RJ, Brazil

${ }^{3}$ Universidade Federal do Estado do Rio de Janeiro (UNIRIO), Hospital Universitário Gaffré e Guinle (HUGG), Rio de Janeiro, RJ, Brazil
}

Date of first submission: June 15, 2020

Last received: May 17, 2021

Accepted: September 30, 2021

Associate editor: Angélica Cavalcanti de Sousa

*Correspondence: lauraoliveira.ft@gmail.com

\begin{abstract}
Introduction: Spinocerebellar ataxia 3 (SCA3) is a hereditary disease associated with progressive cerebellar and extracerebellar degeneration. Although there is no effective therapy for SCA3, some of its symptoms can be relieved with symptomatic treatment. Identifying the presence of this signs in patients may contribute to their clinical management and thus improve their quality of life.

Objective: To identify the presence and frequency of nonataxia signs in a sample of Brazilian individuals with SCA3 and to investigate its association with severity and duration of the disease. Methods: This is a cross-sectional study. The inclusion criteria of this study were participants should be diagnosed with SCA 3 and be between 18 and 70 years old. The exclusion criteria were participants with a score of less than 18 points on the Mini Mental State Examination (MMSE) and those with other neurological or orthopedic problems. Twenty-three participants were evaluated by the Inventory of Non-ataxia Signs (INAS) and the Scale for the Assessment and Rating of Ataxia (SARA). Results: The median score found for INAS was [median (min-max)] 3 (0-6) points and 10 (2-23) for SARA. Only one participant did not show non-ataxic signs. The most prevalent nonataxic manifestations were areflexia, urinary dysfunction, hyperreflexia and spasticity. Spearman correlation test indicated a moderate and significant correlation between INAS and SARA scores $(r h o=0.428,95 \% \mathrm{Cl}=0.39-0.704$, $\mathrm{p}=0.033$ ). There was no association between INAS scores and the disease duration ( $r$ o $=0.003,95 \% \mathrm{Cl}=$ -0.398-0.704, $p=0.393$ ). Conclusion: Areflexia, urinary dysfunction, hyperreflexia and spasticity were the most prevalent non-ataxic signs. We identified a moderate correlation between the presence of non-ataxic signs and disease severity. This findings can help the professionals dealing with these patients.
\end{abstract}

Keywords: Ataxia. Spinocerebellar ataxia type 3. MachadoJoseph disease. Signs and symptoms. 


\section{Resumo}

Introdução: A ataxia espinocerebelar 3 (SCA3) é uma doença hereditária associada à degeneração cerebelar e extracerebelar progressiva. Embora não haja terapia eficaz, alguns sintomas podem ser aliviados com tratamento sintomático. Sendo assim, identificar a presença dos sinais não-atáxicos pode contribuir para o manejo clínico destes indivíduos, melhorando sua qualidade de vida. Objetivo: Identificar a presença e frequência de sinais nãoatáxicos em uma amostra de indivíduos brasileiros com SCA3 e investigar sua associação com a gravidade e duração da doença.

Métodos: Para serem incluídos neste estudo transversal, os participantes deveriam ter diagnóstico de SCA3 e idade entre 18 e 70 anos. Os critérios de exclusão foram pontuação menor de 18 no Mini-exame do estado mental (MEEM), presença de outros problemas neurológicos ou ortopédicos. Vinte e três participantes foram avaliados através do Inventário de Sinais de Não Ataxia (INAS) e Escala de Avaliação e Classificação da Ataxia (SARA). Resultados: A pontuação média encontrada no INAS foi de [mediana (min-máx.)] 3 (0-6) pontos e 10 (2-23) no SARA. Apenas um participante não mostrou sinais não-atáxicos. As manifestações não-atáxicas mais prevalentes foram arreflexia, disfunção urinária, hiperreflexia e espasticidade. O teste de Spearman indicou correlação significativa moderada entre os escores do INAS e do SARA ( $r$ ho = 0,428, IC 95\% = 0,39-0,704, $p=0,033)$. Não houve associação entre os escores do INAS e a duração da doença (rho $=0,003$, IC 95\% $=-0,398-0,704, p$ =0,393). Conclusão: Arreflexia, disfunção urinária, hiperreflexia e espasticidade foram os sinais não atáxicos mais frequentes. Identificamos correlação moderada entre a presença de sinais não atáxicos e a gravidade da doença. Estes resultados podem ajudar os profissionais que lidam com esses pacientes.

Palavras-chave: Ataxia. Ataxia espinocerebelar tipo 3. Doença de Machado-Joseph. Sinais e sintomas.

\section{Introduction}

Spinocerebellar ataxia type 3 (SCA3), also named Machado-Joseph disease, is an autosomal dominantly inherited neurodegenerative disease. It is caused by an elongated polyglutamine stretch that is encoded by abnormal trinucleotide (CAG) expansion in the ATXN3 gene, ${ }^{1,2}$ which results in progressive cerebellar ataxia. ${ }^{3}$ SCA3 was first reported almost five decades ago, in 1972. However it was only in 1994 that the gene related to this disease was identified. ${ }^{4,5}$ Although SCA3 is a rare condition, it is the most common type of spinocerebellar ataxia in the world ${ }^{6}$ and also the most frequent in Brazil $(59-92 \%)^{7}$

Each SCA type has a wide range of clinical manifestations, and their core problems are related to the syndrome that originates by the degenerative course of the disease in the cerebellar region. ${ }^{2,3}$ Cerebellar syndrome comprises gait, speech, and balance disorders. Balance and speech disorders are the most frequent signs and a common initial mark of the disease. ${ }^{8}$ However, the degenerative process of SCA also involves extracerebellar regions such as pons, basal ganglia, midbrain, cranial nerve nuclei, thalamus and frontal, parietal, temporal and occipital lobes, producing non-ataxia manifestations depending on the SCA type. 2,3,9 Specifically, in SCA 3, Parkinsonism, pyramidal signs, peripheral neuropathy, progressive external ophthalmoplegia, urinary dysfunction, pain, cramps, fatigue, dystonia, sleep disorders, cognitive disturbances, psychiatric symptoms and olfactory dysfunction are common non-ataxia findings. 2,3,10

Although there is no effective therapy for SCA3, some of its symptoms can be relieved in patients using symptomatic treatment. This can help to improve patients' quality of life. Non-ataxia signs need to be taken into consideration when setting treatment goals and choosing the appropriate therapeutic approaches. Unfortunately, majority of these non-ataxia signs are often underestimated in clinical practice. In fact, the current physiotherapeutic approach for SCA stated by literature involves balance and coordination training, fall prevention and physical conditioning. ${ }^{11-16}$

The frequency of non-ataxia signs as well as its association with the evolution of the disease has not been systemically investigated in SCA3 individuals. If physical therapists expected to detect the non-ataxia signs from the beginning, these would be earlier identified and would help in the process of setting appropriate goals for physical therapy or early referral of patients to a specialist if necessary. Also, understanding whether the non-ataxic symptoms appear from the onset of the disease or in its more advanced phases can help to draw an action plan for the different phases of the evolution of SCA3. This action plan can improve the quality of the rehabilitation approach for this condition, and also determine success in impacting the quality of life of patients with the disease. Thus, the aims of the present 
study are (i) to identify the presence and frequency of non-ataxia signs in a sample of Brazilian individuals with SCA3, and (ii) to investigate the association between non-ataxia signs and the severity of the disease and the association between these signs and the disease duration.

\section{Methods}

This is a cross-sectional study approved by the local ethics committee (Process Number CAAE 96776818.4.0000.5235). Written consent was obtained from all the study participants.

\section{Participants}

This study used a convenience sample consisted of individuals from local rehabilitation centers. Participants diagnosed with SCA3 by a neurologist and between 18 and 70 years old were included in this study. Participants with a score of less than 18 points ${ }^{17}$ on the Mini Mental State Examination (MMSE), ${ }^{18,19}$ and those having other neurological diseases and orthopedic problems that could limit their gait were excluded from the study.

Of 64 individuals that were contacted by telephone, 23 fulfilled the eligibility criteria and accepted to participate in the study, as shown in Figure 1.

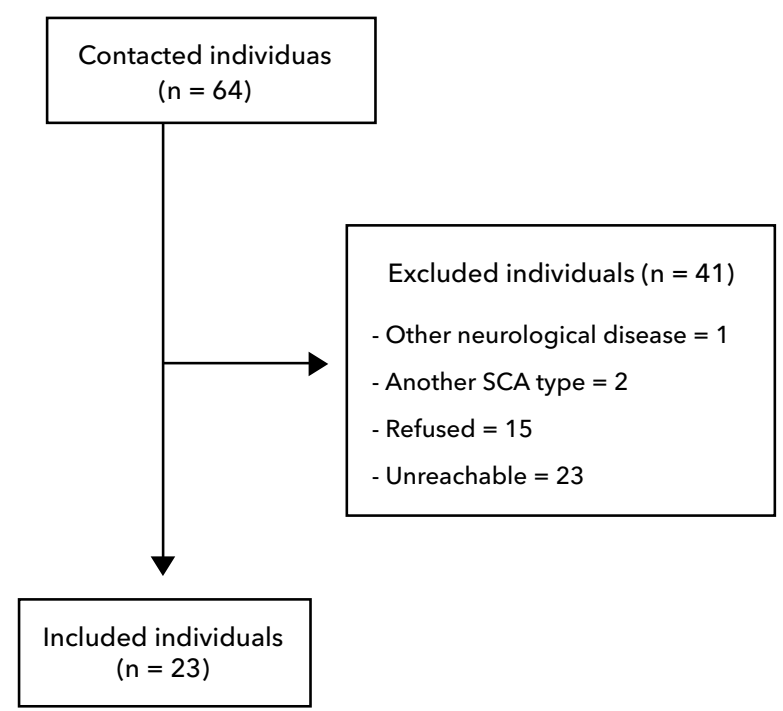

Figure 1 - Process flowchart of recruitment for the study.

Note: SCA = spinocerebellar ataxia.

\section{Procedures}

The recruitment period lasted for three months. The individuals were contacted by telephone and informed about the purpose of the research. After the participants agreed to participate in the study, an initial interview was conducted with them to track their eligibility criteria. Then, they were evaluated in a single session by an expert physiotherapist using the outcome measures.

\section{Outcome measures}

\section{Inventory of Non-ataxia Signs (INAS)}

INAS is an instrument that is highly reliable and easily reproduced. It is used to evaluate the presence of non-ataxia neurological signs and extracerebellar involvement in individuals with SCA. INAS consists of 30 items grouped into 16 non-ataxia signs: areflexia, hyperreflexia, plantar extensor response, spasticity, paresis, amyotrophy, fasciculation, myoclonus, stiffness, chorea, dystonia, resting tremor, sensory symptoms, urinary dysfunction, cognitive dysfunction, and brainstem oculomotor signs. ${ }^{20}$ In the presence of one of these 16 signs, the numeric value 1 is assigned to it and, in their absence, the value 0 is assigned instead. The result is a simple sum that has a minimum score of 0 and a maximum score of 16 , with 0 meaning no impairment and 16 meaning serious impairments. ${ }^{20}$

Scale for the Assessment and Rating of Ataxia (SARA)

SARA is a clinical scale used for a semi-quantitative assessment of cerebellar ataxia at the level of impairment. This scale has eight items that result in a total score of 0 (non-ataxia) to 40 (more severe ataxia). The items are related to gait, stance, sitting, speech, chase test, noseindex test, fast alternating movements, and heel test. ${ }^{21}$

\section{Statistical analysis}

The Shapiro-Wilk test was used to verify the distribution of the data. The sample characteristics, INAS and SARA scores were reported using median, minimum and maximum values. Percentages were used where appropriate. To investigate the association between the variables, the Spearman correlation test (rho) was used. Correlation sizes were defined as: trivial $=$ rho $<0.1$; 
weak $=0.1<$ rho $<0.3 ;$ moderate $=0.3<$ rho $<0.5$; strong $=0.5<$ rho $<0.7$; very strong $=0.7<$ rho $<0.9$; and extremely strong $=$ rho $>0.9 .{ }^{22,23} \mathrm{JASP}$ (Version 0.10.0) was used to analyze statistics. The significance value considered was 0.05 .

\section{Results}

The demographic and clinical data of the participants are shown in Table 1. The median INAS score was [median (min-max)] $3(0-6)$ points and the median SARA score was 10 (2 - 23) points. Only one participant did not show any non-ataxia signs.

Table 1 - Sample's clinical and demographic characteristics

\begin{tabular}{lc}
\hline Variable & Value \\
\hline Number of participants & 23 \\
Age (years) & $51(24-71)$ \\
Sex (M/F) & $7 / 16$ \\
Disease duration (years) & $5(2-16)$ \\
INAS total score & $3(0-6)$ \\
SARA total score & $10(2-23)$ \\
Prevalence of non-ataxia signs (\%) & 95,6 \\
\hline
\end{tabular}

Note: INAS = Inventory of Non-ataxia Signs; SARA = Scale for the Assessment and Rating of Ataxia. Data expressed as number of occurrences or as median (lower-upper values).

The frequencies of the non-ataxia signs found in the study sample were: areflexia (47.82\%), hyperreflexia $(43.47 \%)$, urinary dysfunction $(39.13 \%)$, spasticity (39.13\%), plantar extensor (30.43\%), oculomotor signs (26.08\%), paresis (26.08\%), sensory symptoms $(21.73 \%)$, rigidity (4.34\%) and cognitive dysfunction (4.34\%) (Table 2). The presence of non-ataxic signs for each participant is presented in Table 3.

The Spearman correlation test indicated that there was a moderate and significant correlation between the INAS and SARA scores (rho $=0.428,95 \% \mathrm{Cl}=$ 0.39-0.704, $p=0.033$ ) (Figure 2). In addition, there was no association between the INAS scores and the disease duration ( $r h o=0.003,95 \% \mathrm{Cl}=-0.398-0.704$, $p=0.393)$.
Table 2 - Frequency of non-ataxia signs

\begin{tabular}{lc}
\hline Non-ataxia signs & Frequency - n (\%) \\
\hline Areflexia & $11(47.82)$ \\
Hyperreflexia & $10(43.47)$ \\
Spasticity & $9(39.13)$ \\
Urinary dysfunction & $9(39.13)$ \\
Extensor plantar & $7(30.43)$ \\
Paresis & $6(26.08)$ \\
Brainstem oculomotor signs & $6(26.08)$ \\
Sensory symptoms & $5(21.73)$ \\
Rigidity & $1(4.34)$ \\
Cognitive dysfunction & $1(4.34)$ \\
Muscle atrophy & $0(0.00)$ \\
Fasciculations & $0(0.00)$ \\
Myoclonus & $0(0.00)$ \\
Chorea/dyskinesia & $0(0.00)$ \\
Dystonia & $0(0.00)$ \\
Resting tremor & $0(0.00)$ \\
\hline
\end{tabular}

Note: Data expressed as frequency number and percentage corresponding to sample.

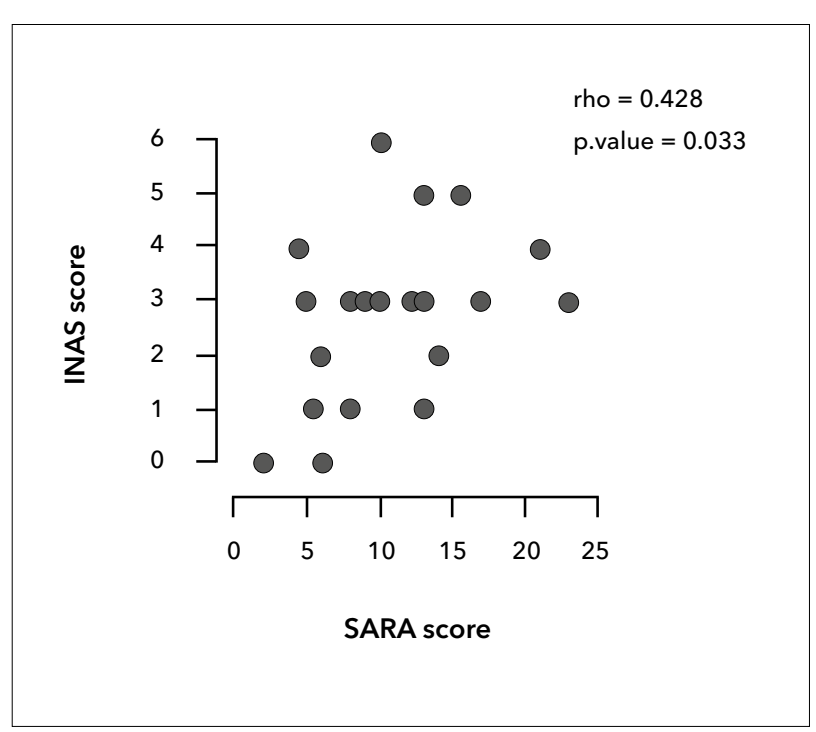

Figure 2 - Scatter-plot representing the relationship between Inventory of Non-ataxia Signs (INAS) and Scale for the Assessment and Rating of Ataxia (SARA) scores. Spearman correlation coefficient (rho) and correspondent $p$-value are shown as inset. 
Table 3 - Presence of non-ataxia signs for each subject with SCA

\begin{tabular}{|c|c|c|c|c|c|c|c|c|c|c|c|}
\hline 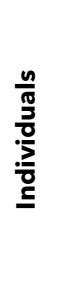 & 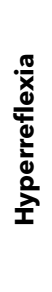 & $\frac{\frac{\pi}{x}}{\frac{0}{\frac{\pi}{\alpha}}}$ & 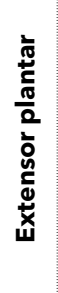 & 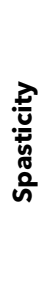 & $\frac{\frac{n}{4}}{\frac{d}{0}}$ & $\frac{7}{\frac{7}{0}}$ & 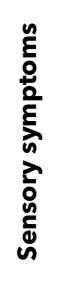 & 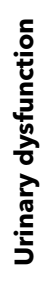 & 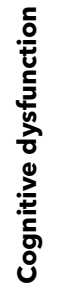 & 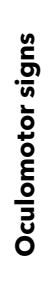 & $\begin{array}{l}\frac{n}{5} \\
\frac{0}{n} \\
\frac{0}{2} \\
\frac{5}{0}\end{array}$ \\
\hline 01 & & $x$ & $x$ & & & & & & & $x$ & \\
\hline 02 & & $x$ & & & & & & $x$ & & & \\
\hline 03 & $x$ & & & $x$ & & & $x$ & & & & \\
\hline 04 & & $X$ & & & $x$ & & & $x$ & & & \\
\hline 05 & & $x$ & $x$ & & $x$ & & $x$ & & & & \\
\hline 06 & & $x$ & & & $x$ & & & $x$ & & & \\
\hline 07 & $x$ & & $x$ & $x$ & & & & & & & \\
\hline 08 & & $x$ & & & & & & & $X$ & & \\
\hline 09 & $x$ & & $X$ & $X$ & & & & $X$ & & & \\
\hline 10 & $x$ & & & $x$ & & & & & & $x$ & \\
\hline 11 & $x$ & & & $x$ & $x$ & & & & & & \\
\hline 12 & $x$ & & $x$ & $x$ & $x$ & & & $x$ & & $X$ & \\
\hline 13 & & & & & & & $X$ & $x$ & & & \\
\hline 14 & $x$ & & $x$ & $x$ & & & & $x$ & & & \\
\hline 15 & & $X$ & & & & & & $x$ & & & \\
\hline 16 & & $X$ & & & & & $x$ & & & $x$ & \\
\hline 17 & & $X$ & & & & & & $x$ & & $x$ & \\
\hline 18 & & & & & & & & & & & \\
\hline 19 & $x$ & & & & $x$ & & & & & & \\
\hline 20 & & $X$ & $x$ & $x$ & & & & & & $X$ & \\
\hline 21 & $x$ & & & $x$ & & & & & & & \\
\hline 22 & & $X$ & & & & & & & & & \\
\hline 23 & $x$ & & & & & $x$ & & & & & \\
\hline
\end{tabular}

Note: SCA = spinocerebellar ataxia; Ind = individuals. The presence of non-ataxic signs for each individual is indicated with a "X". None individual presented muscle atrophy, fasciculation, myoclonus, chorea/dyskinesia, dystonia and resting tremor grouped here as "other symptoms".

\section{Discussion}

This study aims to identify the presence and frequency of non-ataxia signs in a sample of Brazilian individuals with SCA3 and to correlate the presence of these problems with the severity of the disease. From the 23 individuals studied, only one did not present non-ataxia signs. The most frequent non-ataxia signs found were areflexia, urinary dysfunction, hyperreflexia, and spasticity. Rigidity and cognitive dysfunction were the less frequent. We did not find muscle atrophy, fasciculations, myoclonus, chorea/dyskinesia, dystonia and resting tremor in this sample. Finally, there was a moderate and significant correlation between the presence of non-ataxia signs and the severity of the disease.

SCA3 is the most frequent SCA subtype in Brazil and the entire world. This fact motivated the choice for this specific population. ${ }^{6,7}$ The present results demonstrated that $95.6 \%$ of the study participants with SCA3 showed at least one extra-cerebellar sign, suggesting that these signs can be a common feature of this SCA subtype. Yuan et al. ${ }^{24}$ found similar data in a Chinese sample of 68 individuals with SCA3 (91.2\%). All of the non-ataxic signs found in the present study are in accordance with those reported by the literature as being the most common in SCA3. 2,3,10 Among the most prevalent non-ataxia signs found, urinary dysfunction and spasticity are treatable; if they are early detected, they can be properly managed or patients suffering from them can be referred to a specialist.

In the present work, there was a moderate and significant correlation between the presence of nonataxia signs (INAS) and the severity of the disease (SARA). This shows non-ataxia signs have the tendency to increase with the progression of the disease. Similarly, a multicenter European study done with a sample of 139 SCA3 individuals showed a higher correlation (0.61) with the same factor. ${ }^{25}$ On the other hand, we did not find significant correlation between the presence of non-ataxia signs (INAS) and the disease duration. Only Schmitz-Hübsch et al. ${ }^{25}$ previously investigated this association and found a moderate correlation (0.40) between these measures. The difference between these findings may result from the heterogeneity of the sample of SCA subtypes studied in this work (SCA3 only) and by Schimitz- Hubsch et al. (SCA 1, 2, 3, and 6). ${ }^{25}$ Another possible explanation for finding an association between non-ataxic symptoms (INAS) and the severity of ataxia (measured by the SARA scale), but not between non-ataxic signs and the duration of the disease, may be due to different patterns of degeneration among different individuals. It could be that patients with SCA for many years may not have high degree of degeneration caused by ataxia, and consequently high degree of deficiency caused 
by the disease. In some cases, a patient may present an accelerated rate of degeneration with a greater severity of symptoms at the very beginning of the problem. In other words, the severity of the disease as measured by SARA appears to be more important than the duration (in years) of the disease in determining the appearance of non-ataxic signs in SCA3.

The median INAS scores found here (3.0 points in 23 individuals) are similar to the findings of a Chinese study which reported a mean INAS score of 2.30 in 68 individuals with $\mathrm{SCA} 3,{ }^{24}$ and to a German study that reported a mean INAS score of 1.1 in 15 individuals. ${ }^{26}$ However, the multicenter European study referred to above found a higher score (5.2) in a sample of 139 individuals with SCA3. ${ }^{25}$ The different scores found may be due to the different levels of impairment of the samples as measured by SARA scale. In fact, SchmitzHübsch et al. ${ }^{25}$ found a higher SARA score (15.1) compared to those of other studies: 10 in the present study, 8.2 in Klinke et al., $^{26}$ and 11.1 in Yuan et al. ${ }^{24}$ Furthermore, the ethnic differences of patients related to genes mutations that can occur worldwide can lead to clinical heterogeneity. ${ }^{24,27}$

Among the extra-cerebellar signs, areflexia was the most frequent sign found in this study (47.82\%). It is similar to the results reported by Klinke et al. ${ }^{26}$ and Schmitz-Hübsch et al. ${ }^{25}$ (both including European populations). On the other hand, Yuan et al. ${ }^{24}$ reported $6 \%$ of areflexia in their Chinese sample of individuals. The presence of peripheral motor signs is common in SCA3 and has been associated with age, disease duration and age at onset. ${ }^{25,28}$

Hyperreflexia was the second most frequent sign in this study (43.47\%), followed by spasticity (39.13\%). The presence of pyramidal signs is also common in SCA3. In fact, Yuan et al. ${ }^{24}$ and Schmitz-Hübsch et al. ${ }^{25}$ reported a high prevalence of pyramidal signs in SCA3. The presence of these signs can be influenced by repeat length of expanded allele and associated age at onset, but they are not influenced by disease duration. ${ }^{25}$

Urinary dysfunction includes frequency, urgency, incontinence, nocturia and incomplete emptying symptoms. These are common non-ataxia manifestations in SCA3 disease, observed in up to $50 \%$ of the study participants. ${ }^{29}$ Thirty-nine point thirteen percent (39.13\%) of the study sample showed urinary dysfunction. Studies regarding the occurrence of this manifestation in
SCA and its treatment could provide basis for further investigations.

Rigidity (4.34\%) and cognitive dysfunction (4.34\%) were the less frequent non-ataxia signs in this study. In two other studies, rigidity frequency was measured to be $10 \%$ on average. ${ }^{25,30}$ In a study including 15 individuals, only one presented rigidity. ${ }^{26}$ However, this was the most frequent sign $(47.1 \%)$ in a Chinese study population. ${ }^{24}$ The cognitive dysfunction was not reported by Klinke et al. ${ }^{26}$ On the other hand, Yuan et al. ${ }^{24}$ and Schmitz-Hübsch et al. ${ }^{25}$ reported a frequency of cognitive dysfunction of $10 \%$ and $19 \%$, respectively.

This study comprised a relatively small sample size, which may compromise the external validity of these findings. This relatively small sample size was a result of difficulty locomotion of individuals with SCA and owing to the poor public transportation in Brazil which restricted the participation of the individuals with SCA in this study. Even though the sample was not very big, the data presented here can guide physical therapists about the non-ataxic signs that should be expected in individuals with SCA3 at least in Brazil.

\section{Conclusion}

The results obtained here suggest that: (i) most patients with SCA3 may present at least one non-ataxic sign besides the classical signs of cerebellar syndrome. Areflexia was the most common extra-cerebellar sign, followed by hyperreflexia and urinary dysfunction; and (ii) the higher the degree of severity of SCA, the greater the probability of more non-ataxic signs. It is very relevant for physical therapists to keep this information in mind when evaluating and designing the therapeutic plan for individuals with this disease. Cerebellar syndrome and non-ataxic signs must be considered in this plan in order to promote an intervention with a greater chance of success. These findings can contribute to the clinical management of individuals with SCA3.

\section{Authors' contributions}

CPM, YRLA and FBLF: data acquisition and analysis. CPM, MSSKG, LASO: manuscript writing. LASO: research design and critical review. 


\section{References}

1. Wang C, Chen Z, Yang F, Jiao B, Peng H, Shi Y, et al. Analysis of the GGGGCC repeat expansions of the C9orf72 Gene in SCA3/ MJD Patients from China. PLoS One. 2015;10(6): e0130336. DOI

2. Paulson H. Machado-Joseph disease/spinocerebellar ataxia type 3. Handb Clin Neurol. 2012;103:437-49. DOI

3. Klockgether T, Mariotti C, Paulson HL. Spinocerebellar ataxia. Nat Rev Dis Primers. 2019;5(1):24. DOI

4. Nakano KK, Dawson DM, Spence A. Machado disease: A hereditary ataxia in Portuguese emigrants to Massachusetts. Neurology. 1972;22(1):49-55. DOI

5. Kawaguchi $Y$, Okamoto T, Taniwaki M, Aizawa M, Inoue $M$, Katayama $S$, et al. CAG expansions in a novel gene for Machado-Joseph disease at chromosome 14q32.1. Nat Genet. 1994;8(3):221-8. DOI

6. Hersheson J, Haworth A, Houlden H. The inherited ataxias: genetic heterogeneity, mutation databases, and future directions in research and clinical diagnostics. Hum Mutat. 2012;33(9):1324-32. DOI

7. Castilhos RM, Furtado GV, Gheno TC, Schaeffer P, Russo A, Barsottini $O$, et al. Spinocerebellar ataxias in Brazil-frequencies and modulating effects of related genes. Cerebellum. 2014;13(1):17-28. DOI

8. Nanetti L, Alpini D, Mattei V, Castaldo A, Mongelli A, Brenna G, et al. Stance instability in preclinical SCA1 mutation carriers: A 4-year prospective posturography study. Gait Posture. 2017;57: 11-4. DOI

9. Pedroso JL, França Jr MC, Braga-Neto P, D'Abreu A, SaraivaPereira $\mathrm{ML}$, Saute JA, et al. Nonmotor and extracerebellar features in Machado-Joseph disease: a review. Mov Disord. 2013;28(9):1200-8. DO।

10. Sequeiros J, Coutinho P. Epidemiology and clinical aspects of Machado-Joseph disease. Adv Neurol. 1993;61:139-53. PubMed

11. Ilg W, Synofzik M, Brötz D, Burkard S, Giese MA, Schöls L. Intensive coordinative training improves motor performance in degenerative cerebellar disease. Neurology. 2009;73(22):182330. DOI
12. Miyai I, Ito M, Hattori N, Mihara M, Hatakenaka M, Yagura $\mathrm{H}$, et al. Cerebellar ataxia rehabilitation trial in degenerative cerebellar diseases. Neurorehabil Neural Repair. 2012;26(5): 515-22. DOI

13. Martins CP, Rodrigues EC, Oliveira LAS. Physical therapy approach to spinocerebellar ataxia: a systematic review. Fisioter Pesqui. 2013;20(3):286-91. DOI

14. Schatton C, Synofzik M, Fleszar Z, Giese MA, Schöls L, Ilg W. Individualized exergame training improves postural control in advanced degenerative spinocerebellar ataxia: A rater-blinded, intra-individually controlled trial. Parkinsonism Relat Disord. 2017;39:80-4. DOI

15. Wang RY, Huang FY, Soong BW, Huang SF, Yang YR. A randomized controlled pilot trial of game-based training in individuals with spinocerebellar ataxia type 3. Sci Rep. 2018;8(1):7816. DOI

16. Oliveira LAS, Martins $C P$, Horsczaruk CHR, Silva $D C L$, Vasconcellos LF, Lopes AJ, et al. Partial body weight-supported treadmill training in spinocerebellar. Rehabil Res Pract. 2018;2018:7172686. DO

17. Castro-Costa E, Fuzikawa C, Uchoa E, Firmo JOA, Lima-Costa MF. Norms for the mini-mental state examination adjustment of the cut-off point in population-based studies (evidences from the Bambui health aging study). Arq Neuro-Psiquiatr. 2008;66(3A):524-8. DOI

18. Folstein MF, Folstein SE, McHugh PR. "Mini-mental state": A practical method for grading the cognitive state of patients for the clinician. J Psychiatr Res. 1975;12(3):189-98. DOI

19. Almeida OP. Mini exame do estado mental e o diagnóstico de demência no Brasil. Arq Neuro-Psiquiatr. 1998;56(3B):60512. DOI

20. Jacobi H, Rakowicz M, Rola R, Fancellu R, Mariotti C, Charles $P$, et al. Inventory of Non-Ataxia Signs (INAS): validation of a new clinical assessment instrument. Cerebellum. 2013;12(3):418-28. $\mathrm{DOl}$

21. Schmitz-Hübsch T, Montcel ST, Baliko L, Berciano J, Boesch $S$, Depondt $C$, et al. Scale for the assessment and rating of ataxia: development of a new clinical scale. Neurology. 2006;66(11):1717-20. DOI 
22. Cohen J. Statistical power analysis for the behavioral sciences. 2nd ed. Hillsdale, NJ: Lawrence Erlbaum Associates; 1998.

23. Hopkins WG, Marshall SW, Batterham AM, Hanin J. Progressive statistics for studies in sports medicine and exercise science. Med Sci Sports Exerc. 2009;41(1):3-13. DOI

24. Yuan X, Ou R, Hou Y, Chen X, Cao B, Hu X, et al. Extracerebellar signs and non-motor features in Chinese patients with spinocerebellar ataxia type 3. Front Neurol. 2019;10:110. $\mathrm{DOI}$

25. Schmitz-Hübsch T, Coudert M, Bauer P, Giunti P, Globas C, Baliko L, et al. Spinocerebellar ataxia types 1, 2, 3, and 6: disease severity and nonataxia symptoms. Neurology. 2008;71(13):9829. DOI

26. Klinke I, Minnerop M, Schmitz-Hübsch T, Hendriks M, Klockgether T, Wüllner $U$, et al. Neuropsychological features of patients with spinocerebellar ataxia (SCA) types 1, 2, 3, and 6 . Cerebellum. 2010;9(3):433-42. DOI
27. Jacobi H, Bauer P, Giunti P, Labrum R, Sweeney MG, Charles $P$, et al. The natural history of spinocerebellar ataxia type 1, 2, 3, and 6: a 2-year follow-up study. Neurology. 2011;77(11):103541. DOI

28. Klockgether T, Schöls L, Abele M, Bürk K, Topka H, Andres $\mathrm{F}$, et al. Age related axonal neuropathy in spinocerebellar ataxia type 3/Machado Joseph disease (SCA3/MJD). J Neurol Neurosurg Psychiatry. 1999;66(2):222-4. DOI

29. Musegante AFA, Almeida PNS, Barboza AL, Barroso Jr U. Urinary symptoms and urodynamic findings in patients with Machado-Joseph disease. J Neurol. 2011;258(4):623-6. DOI

30. Jhunjhunwala K, Netravathi M, Purushottam M, Jain S, Pal PK. Profile of extrapyramidal signs in 85 patients with spinocerebellar ataxia type 1, 2 and 3. J Clin Neurosci. 2014;21(6):1002-6. DOI 